\title{
The comprehensive assessing of the economic development conditions of cities in Shandong province*
}

\author{
Guoliang Cai $^{1 \dagger}$, Lei Zhang ${ }^{1,2}$ \\ 1 Faculty of science, Jiangsu University, Zhenjiang, 212013, China \\ 2 Jinan Statistics Bureau of Lixia District, Jinan, 250014, China
}

(Received May 12 2007, Accepted October 21 2007)

\begin{abstract}
In this article, we analyze the current conditions of cities in Shandong province by using multivariate statistical method and find out their comparative advantage and weakness. Then, we make some suggestions to improve economic development of their own.
\end{abstract}

Keywords: assess, principal component analysis, cluster analysis, Shandong province

\section{Introduction}

Shandong province is located in the junction between Yellow River Economic Belt and Around Bohai Economic Region, and the connection between North China and East China. Due to its special location and advantaged natural resources, Shandong plays an important role in the national economic structure. With China's reform and opening up, there is a sustainable, fast and healthy development. The industrial structure has become more and more reasonable and the economic benefit has become greater and greater. The GDP is increasing at the rate of $10 \%$. The main index for national economy is in the front rank of the whole nation and has become a big economic coastal province of the east of China. However, Shandong's economic development is also facing the problem which is common in the process of our national economic development - the unbalance of regional economic development which will surely influence the unbalance of the social development, thereby influencing the sustainable development of the whole region. Therefore, analyzing the cause of the existence of regional difference and finding out the way to solve the problems are the key to ensuring a further development of Shandong's society and economy. The article adopts the method of principal component analysis, cluster analysis separately to give a comprehensive appraisal to the economic development of all cities of this province, compare their competitiveness, advantages and disadvantages of their competition, analyze the unbalance of the regional economies and offer some advice and reference for its sustainable economic development.

\section{The choice of the economic and social development level appraisal index}

Based on the principals of scientific content, objectivity, dependability, comparability, we choose the following indices as the index system of the appraisal of economic development level.

\footnotetext{
* This research was supported by the National Social Science Foundation of China (No. 02BJY051), and the Department of Education Foundation of Jiangsu Province (No. 03SBJ790008).

${ }^{\dagger}$ Corresponding author. Tel.: +44-773-248 8965; fax: +44-773-248 8965.

E-mail address: info@wjms.org.uk.
} 
GDP $\left(X_{1}\right)$ and Per-capita GDP $\left(X_{2}\right)$ : a reflection of the economic development level of a total region; Per-capita the value-added of the primary industry $\left(X_{3}\right)$ : a reflection of the agricultural development level of a region; Per-capita industrial added value $\left(X_{4}\right)$ : a reflection of the development level of the industria-lization of a region; Per-capita tertiary industrial added value $\left(X_{5}\right)$ : a reflection of the development level of the tertiary industry; Per-capita financial income $\left(X_{6}\right)$ : a reflection of the financial strength of a region; Per-capita total retail sales of consumer goods Amount $\left(X_{7}\right)$ : a reflection of the market capacity and the consuming level of a region; Per-capita fixed assets investment $\left(X_{8}\right)$ : a reflection of the investment level to the economic and social development of a region; Per-capita post and tele business volume $\left(X_{9}\right)$ : a reflection of social service facilities level. Per-capita export amount $\left(X_{10}\right)$ : a reflection of the regional international economy development level and opening- up level; Average salary $\left(X_{11}\right)$ : a reflection of the income of the residents of a region. The above data comes from 2005 annual statistics of Shandong.

Table 1. Main index of Shandong economic development level in 2004

\begin{tabular}{c|l|l|l|l|l|l|l|l|l|c|c}
\hline \multirow{2}{*}{ City } & $\begin{array}{l}X_{1} \\
(\text { Yuan) }\end{array}$ & $\begin{array}{l}X_{2} \\
\text { (Yuan) }\end{array}$ & $\begin{array}{l}X_{3} \\
(\text { Yuan) }\end{array}$ & $\begin{array}{l}X_{4} \\
(\text { Yuan) }\end{array}$ & $\begin{array}{l}X_{5} \\
\text { (Yuan) }\end{array}$ & $\begin{array}{l}X_{6} \\
\text { (Yuan) }\end{array}$ & $\begin{array}{l}X_{7} \\
\text { (Yuan) }\end{array}$ & $\begin{array}{l}X_{8} \\
\text { (Yuan) }\end{array}$ & $\begin{array}{l}X_{9} \\
\text { (Yuan) }\end{array}$ & $\begin{array}{l}X_{10} \\
\text { (U.S. dollar) }\end{array}$ & $\begin{array}{l}X_{11} \\
\text { (Yuan) }\end{array}$ \\
\hline Jinan & 1618.87 & 27434.90 & 2011.60 & 12581.41 & 12841.89 & 1508.90 & 10523.85 & 9280.43 & 999.87 & 232.69 & 17837 \\
Qingdao & 2163.80 & 29595.57 & 2213.03 & 16021.93 & 11360.61 & 1785.11 & 8281.71 & 10649.63 & 1135.24 & 2158.55 & 17189 \\
Zibo & 1230.96 & 29662.57 & 1302.69 & 19202.98 & 9156.90 & 1205.73 & 7224.91 & 6056.97 & 843.40 & 349.55 & 15192 \\
Zaozhuang & 503.31 & 13785.91 & 1492.51 & 8458.73 & 3834.67 & 567.17 & 3843.95 & 3674.29 & 449.20 & 69.94 & 13021 \\
Dongying & 891.85 & 49871.58 & 2278.15 & 40273.60 & 7319.83 & 1583.25 & 6547.98 & 21479.42 & 1191.08 & 338.65 & 23909 \\
Yantai & 1630.89 & 25213.87 & 2647.25 & 14296.19 & 8270.43 & 989.79 & 6808.97 & 9603.69 & 646.25 & 694.94 & 15446 \\
Weifang & 1246.41 & 14652.42 & 2120.73 & 8034.90 & 4496.79 & 618.13 & 4763.49 & 5318.22 & 587.78 & 250.06 & 12329 \\
Jining & 1102.16 & 13737.46 & 1901.65 & 7090.21 & 4745.60 & 673.76 & 3662.17 & 3888.00 & 377.66 & 102.80 & 13608 \\
Taian & 732.11 & 13312.36 & 1706.53 & 7021.39 & 4584.44 & 567.57 & 4076.43 & 3223.88 & 365.49 & 81.85 & 11837 \\
Weihai & 1008.81 & 40614.14 & 3982.06 & 24813.11 & 11818.97 & 1716.70 & 9587.23 & 15599.14 & 970.25 & 1388.71 & 13071 \\
Rizhao & 387.78 & 13825.55 & 2231.17 & 6814.02 & 4780.36 & 400.38 & 3725.65 & 4737.44 & 449.23 & 385.76 & 11648 \\
Laiwu & 223.88 & 18012.27 & 1362.10 & 11377.95 & 5272.22 & 828.28 & 5398.41 & 7266.10 & 506.87 & 349.80 & 15619 \\
Linyi & 1012.00 & 9970.04 & 1448.61 & 5235.26 & 3286.17 & 370.20 & 3053.12 & 2599.15 & 376.34 & 111.20 & 11076 \\
Dezhou & 686.90 & 12504.99 & 2152.55 & 6567.26 & 3785.18 & 442.80 & 3408.13 & 5668.90 & 396.87 & 82.78 & 9260 \\
Liaocheng & 572.69 & 10109.74 & 2053.48 & 5552.79 & 2503.47 & 396.02 & 2247.69 & 2511.15 & 406.03 & 64.24 & 10919 \\
Binzhou & 519.45 & 14081.13 & 2187.87 & 8133.41 & 3759.85 & 596.55 & 3195.25 & 6223.64 & 509.63 & 245.03 & 11680 \\
Heze & 365.04 & 4144.92 & 1544.24 & 1684.47 & 916.21 & 195.58 & 2014.31 & 1186.99 & 253.21 & 78.59 & 8733 \\
\hline
\end{tabular}

\section{The analysis and appraisal of the development conditions of the cities in shandong}

The text will use two different methods to appraise the development conditions of the cities in Shandong to get an objective result.

\subsection{Principal component analysis}

Principal component analysis is a multivariate statistics, which is to provide large quantities of information by withdrawing a few comprehensive elements from many elements without changing the original ones. By way of mathematical manipulation, making new variants (main components) become the linear combination of the original variants; and we choose a few main components from information of bigger total deviation to analyze things. Therefore the higher percentage some main component takes in the total dispersion, the more effects it has in the overall evaluation. In the process of transforming the original variants into the main components, many new main components and their weight numbers are formed, so that the principal component analysis overcomes the subjective human factor before picking up the indices; then the results of the total evaluation are helpful to objectively value the relations among the samples.

According the data in Tab. 1, we could get the correlation matrix by using Spss 14.0. Then we could work out the eigenvalue, contribution ratio and the accumulated contribution ratio, as it is presented on Tab. 2 . 
Table 2. Total variance explained

\begin{tabular}{c|c|c|c}
\hline \multirow{2}{*}{ Component } & \multicolumn{3}{|c}{ Initial Eigenvalues } \\
\cline { 2 - 4 } & Total & \% of Variance & Cumulative\% \\
\hline 1 & 7.863 & 71.481 & 71.481 \\
2 & 1.320 & 11.995 & 83.476 \\
3 & 0.981 & 8.922 & 92.398 \\
4 & 0.377 & 3.425 & 95.823 \\
5 & 0.270 & 2.457 & 98.280 \\
6 & 0.093 & 0.846 & 99.125 \\
7 & 0.046 & 0.421 & 99.547 \\
8 & 0.025 & 0.231 & 99.778 \\
9 & 0.016 & 0.146 & 99.924 \\
10 & 0.008 & 0.076 & 100.000 \\
11 & $2.57 \mathrm{E}-016$ & $2.34 \mathrm{E}-015$ & 100.000 \\
\hline
\end{tabular}

From Tab. 2, the variant matrix has two biggest latent roots: 7.863 and 1.320. Both of them can explain the total variance $83.476 \%$ (the accumulated contribution ratio). This shows that the former factors could generalize enough information of the original numbers, so here we respectively choose the two factors as the first component and the second one. After standardizing the original values, we could get the component matrix, as it is presented on Tab. 3 .

Use the data from Tab. 3 to divide the eigenvalues responding to the main factors and sqrt the results, and then we will get the coefficient in correspondence to each index. That means data of the first line from Tab. 3 divide $\sqrt{7.863}$, data of the second line do $\sqrt{1.320}$.

Table 3. Component Matrix

\begin{tabular}{c|c|c|c|c|c|c|c|c|c|c|c}
\hline \multirow{2}{*}{ Component } & \multicolumn{10}{c}{ Index } \\
\cline { 2 - 26 } & $X_{1}$ & $X_{2}$ & $X_{3}$ & $X_{4}$ & $X_{5}$ & $X_{6}$ & $X_{7}$ & $X_{8}$ & $X_{9}$ & $X_{10}$ & $X_{11}$ \\
\hline 1 & 0.653 & 0.952 & 0.550 & 0.857 & 0.907 & 0.983 & 0.906 & 0.896 & 0.972 & 0.697 & 0.809 \\
\hline 2 & 0.539 & -0.270 & 0.232 & -0.473 & 0.286 & 0.066 & 0.211 & -0.341 & -0.046 & 0.508 & -0.414 \\
\hline
\end{tabular}

Suppose $Z_{1}$ and $Z_{2}$ respectively stand for the first main component and the second component, we can get such expressions.

$$
\begin{aligned}
Z_{1}= & 0.233 \times x_{1}^{*}+0.340 \times x_{2}^{*}+0.196 \times x_{3}^{*}+0.306 \times x_{4}^{*}+0.323 \times x_{5}^{*}+0.351 \times x_{6}^{*}+0.323 \times x_{7}^{*} \\
& +0.320 \times x_{8}^{*}+0.347 \times x_{9}^{*}+0.249 \times x_{10}^{*}+0.289 \times x_{11}^{*} \\
Z_{2}= & 0.469 \times x_{1}^{*}-0.235 \times x_{2}^{*}+0.202 \times x_{3}^{*}-0.412 \times x_{4}^{*}+0.249 \times x_{5}^{*}+0.057 \times x_{6}^{*}+0.184 \times x_{7}^{*} \\
& -0.297 \times x_{8}^{*}-0.040 \times x_{9}^{*}+0.442 \times x_{10}^{*}-0.360 \times x_{11}^{*}
\end{aligned}
$$

where $x_{j}^{*}(j=1,2,3 \cdots 10)$ in the expressions are standardized index of $x_{j}^{*}$. The contribution ratio of the 1st main component is $71.481 \%$, so it is the most powerful index; the contribution ratio of the 2 nd main component is $11.995 \%$, and the per capita added value of the primary industry and the per capita output value are heavily loaded; the other coefficients are relatively small or minus.

Suppose $Z$ is the comprehensive score, combine $Z_{1}, Z_{2}$ according to the contribution ratio, as the followed weight:

$$
Z=Z_{1} * \lambda_{1} /\left(\lambda_{1}+\lambda_{2}\right)+\Delta\left|Z_{2}\right| * \lambda_{2} /\left(\lambda_{1}+\lambda_{2}\right)
$$

$\Delta=\operatorname{Sgn}\left(X_{1}+X_{2}+\cdots X_{10}\right)$, and $\lambda_{1}, \lambda_{2}$ respectively stands for the 1 st, 2 nd eigenvalues.

So we can get $Z=0.856 \times Z_{1}+0.144 \times Z_{2}$; at last we can get the scores of the factors and the ordering form by Spss14.0, as it is presented on Tab. 4. 
Table 4. Component Score

\begin{tabular}{l|c|c|c|c}
\hline City & $Z_{1}$ & $Z_{2}$ & $Z$ & Order \\
\hline Jinan & 3.12 & 0.64 & 2.76 & 4 \\
Qingdao & 4.42 & 2.26 & 4.11 & 1 \\
Zibo & 1.5 & -0.25 & 1.25 & 6 \\
Zaozhuang & -1.82 & -0.57 & -1.64 & 13 \\
Dongying & 4.96 & -3.5 & 3.74 & 3 \\
Yantai & 1.69 & 0.8 & 1.56 & 5 \\
Weifang & -0.79 & 0.52 & -0.6 & 7 \\
Jining & -1.35 & 0.19 & -1.13 & 9 \\
Taian & -1.83 & 0.01 & -1.57 & 12 \\
Weihai & 4.66 & 0.84 & 4.10 & 2 \\
Rizhao & -1.64 & 0.01 & -1.4 & 11 \\
Laiwu & -0.65 & -1.07 & -0.71 & 8 \\
Linyi & -2.4 & 0.27 & -2.01 & 15 \\
Dezhou & -2.01 & 0.14 & -1.7 & 14 \\
Liaocheng & -2.55 & -0.08 & -2.19 & 16 \\
Binzhou & -1.47 & -0.25 & -1.3 & 10 \\
Heze & -3.84 & 0.03 & -3.28 & 17 \\
\hline
\end{tabular}

\subsection{Cluster method}

Cluster method is a way of sorting the subject investigated according to their characteristics, finding out the similar statistics among the valued samples through many observation indices of a set of samples and sorting them so that the samples of the same cluster have high homogeneity and the samples of different cluster have high nonhomogeneity, forming the most similar samples from a small cluster to a main cluster until all samples are clustered. Using cluster method to analyze the developing levels of economy in every city could help us to better understand the differences of the developing levels of economy in each city.

In order to value how similar are the valued samples, the Squared Euclidean distance is adopted as the standards in this text, that is:

$$
D=\left(x_{1}-y_{1}\right)^{2}+\left(x_{2}-y_{2}\right)^{2}+\cdots
$$

And the Between-groups linkage is chosen as the cluster method.

With Spss 14.0 and the statistics from Tab. 1, cities in Shandong, after cluster analysis, could be divided into three clusters, as it is presented on Tab. 5 .

Table 5. Result of Cluster Analysis

\begin{tabular}{l|l}
\hline Cluster 1 & Jinan, Qingdao, Yantai, Zibo, Dongying \\
\hline Cluster 2 & Zaozhuang, Weifang, Taian, Rizhao, Laiwu, Linyi, Dezhou, Liaocheng, Binzhou \\
\hline Cluster 3 & Heze \\
\hline
\end{tabular}

\section{Result analysis}

By ways of the above, we could get the results as follows: Dongying, Weihai, Jinan, Qingdao, Yantai and Zibo are better developing cities. As the provincial city, Jinan is the economic and cultural center and its development level of economy ranks in the front; Qingdao and Yantai, the main coastal cities in China, are highly open to the outside and the level of making use of the foreign investment is pretty highparticularly, the industry and manufacturing of Qingdao are well-known in China; Weihai, which is also a coastal open city, recently has developed very fast and utilized much foreign investment; additionally tourism is an important factor in pulling its economy forward; although Dongying's index is not very high in the gross amount, it has 
small population; accordingly the per capita index ranks in the front. Shengli oil field, the second largest oil field in China, plays an obvious role in the economy. Zibo, the base of Shandong's heavy industry, also ranks in the front in terms of every index.

Heze, which develops the least, has a population of 8,800,000 (about 9\% of Shandong's population). But its total output value only accounts for lower than $3 \%$ of Shandong's. And per capita index of economy is far lower than the average level of Shandong.

The number of the second-cluster cities is bigger. The economy in these cities has developed into a certain scale and a certain level. Although the developing conditions are different, they are basically at the same level.

\section{Conclusions and suggestions}

In recent years, with high speed of development of cities in Shandong province, new and in-depth problems follow. What is more, Shandong province ranks second in population; and the peasants take high percentage. Although the number of cities is big, the scale is relatively small. The facilities are so legged behind, and the capacity is till not very strong enough. The above are the features of cities in Shandong province.

Then, the advantages of central cities are not very obvious so that they have great impact on the economic development in Shandong province. The more developed areas are filled with one or more central cities, which are characterized with large scales and strong capacity. They play leading roles. With exception of Jinan and Qingdao, the southern and northern areas are lack of central cities. Even if compared with other provincial cities in the costal areas, Jinan has no advantages at all. Dezhou, Liaocheng in the northwest and Heze in the southwest in Shandong province were established not long ago; Though the scales have developed a lot, the total competitive ability being strenthened, due to the higher densely-populated people in villages around, they can not take the lead in the distant cities.

Then, scientific strategic development mode should be adopted. The key point is to develop the cities in Shandong Peninsula. It should be insisted on the growth of central cities and extending city circle, so that they could develop depending each other. Finally, Shandong will be developed into one of the highest open, the most competitive and the most active places in China. The suggestions are as follows.

First, Jinan is the provincial city of Shandong province and takes the lead in Shandong economic development. It should be positioned as the political, cultural and educational center; the transport junction and economic centre; a comprehensive city with modern service as its leading industry and high and new advanced technique.

Second, as the bridgehead of Shandong province, Qingdao makes great efforts on developing manufacturing and exportation processing industry and increasingly utilizes foreign investment. What's more, Qingdao, regarding Olympic Games as an opportunity, develops its competitive ability, working hard to develop it into a modern metropolis.

Third, coastal cities such as Yantai, Weihai and Rizhao, using their own advantages, make themselves more open, enlarge the handling capacity of the ports, increasingly utilizes foreign investment, lead the growth of local enterprises, provide support for the local medium and small companies and strengthen the competitive ability.

Fourth, Dongying and Zibo are the cities with highly developed heavy industry. They, using their advantages in resource, could develop their competitive industries; Dongying, depending on Shengli oil field, could develop oil and chemical industries; Zibo has its special manufacturings, being led by petrifaction, medcine and new materials.

The above cities have one in common, that is they are located in peninsular areas. The next step is speeding up the development in peninsular areas, which should be considered as an important strategy. In some way, speeding up the local economic development is a key pathway to catch up with the other advanced provinces. Comparing the advanced provinces, such as Guangdong and Jiangsu, the gap is not lying in poor areas. Guangdong has its northern part, a poor area; the northern part in Jiangsu is a poor area as well. The gap lies in Shandong has no advantage in advanced areas. Focusing on supporting the development of the peninsular areas is an effective way to overtaking the developed areas. 
Fifth, the development evels of Taian, Laiwu, Dezhou, Liaocheng, Binzhou, Weifang, and Linyi are different; however, generally speaking, they have their own advantages, so developing the competitive industries is the next step. Taian, depending on its rich tourism resources, could combine with Jinan's springs tourism and form its unique "water and mountains" tourism. Laiwu is good at steel, clothes, food processing, turism and special farming; Dezhou's manufacturing and chemical industry, Liaocheng's machine building industry, medicine, Binzhou's spinning have developed into a certain scale; Linyi and Weifang should further develop its advantages on traditional farming; additionally they need to make great effort on the development of machine and processing, carry out the "strengthening cities with industries" strategy, actively transformer the way of economic growth, speed up the adjustment industrial structures, increase the percentage of the secondary industry in the national economy.

Sixth, the whole development level of Jining, Zaozhuang and Heze are not high. The basic reason is the low speed of industrializtion. The next action is to establish a city circle with Jining as its center and with Zaozhuang and Heze as its two wings. Jining is one of the six central cities in Shandong province. The GDP is up to and over RMB100 billion, the financial income up to RMB10 billion. It has great potential in location, economy and city scale and so on. As two wings, Zaozhuang is an important base of coal, building material and coal chemical industry. Heze is an important city located in the junction of Jiangsu, Shandong and Anhui. It is also the bases of energy and food and agricultural byproducts. The key point is to keep the development of the three cities closely connected and intensify the economic exchange among the three cities; Avert the mutual benefit of resource and technology; Learn the development experience from advanced cities. Much effort need to be focused on the following four leading industries: coal chemical industry, machine building, building materials and spinning.

\section{References}

[1] Y. Cai. The application of principal component analysis in the comprehensive appraisal. China Statistics, 2005, 24-26.

[2] Hotelling. Analysis of a complex of statistical variables into principal components. 1993, 24: 417-441.

[3] X. Li. Grads analysis and strategic suppose of shandong regional economic development. Geographic Reaserch, 1995, 14: 50-58.

[4] D. Qiu. Systematic analysis on multi-index comprehensive appraisal method. China Statistics Press, 1991.

[5] V. Smidl, A. Quinn. On bayesian principal component analysis. Computational Statistics \& Data Analysis, 2007, 9: 4101-4123.

[6] J. Wang, Y. Yu. Research on the principal component analysis of urban comprehensive economic strength. Business Research, 2004, 1: 15-18.

[7] H. Wei. The application of SPSS 10.0 for Windows in the economic management. China Statistic Press, 2000.

[8] M. Yamamoto, S. Takakazu, et. al. Correlation analysis of principal components from two populations. Computational Statistics \& Data Analysis, 2007, 9: 4707-4716.

[9] L. Yang. Research on the cluster analysis method. Telecommunication University School Journal, 2003, 5.

[10] X. Yin. Factor analysis of comprehensive economic strength of all districts and counties of chongqing city. Chongqing University School Journal, 2001, 1: 4-6.

[11] K. Zhu. Measuring index system and calculation analysis of the eastern and western areas of shandong province. Research on Geography and Country, 2000, 16: 87-91. 